\title{
Farelo de biscoito na alimentação de porcas em lactação ${ }^{1}$
}

\author{
Anderson Corassa ${ }^{2}$, Rozangela Teresinha Prezotto ${ }^{2}$, \\ Cláudia Marie Komiyama², Paulo Sérgio Andrade Moreira ${ }^{2}$, Cláudio Vieira de Araújo ${ }^{2}$
}

\begin{abstract}
Biscuit bran for feeding lactating sows

Biscuit bran can be alternatively used as a partial or total substitute for conventional ingredients, however, it is necessary to evaluate the impact of its inclusion. Thus, this study aimed at evaluating the inclusion of biscuit bran in diets of lactating sows. A total of 16 lactating sows was used in a completely randomized design, with four treatments and each sow being considered an experimental unit. Treatments consisted of inclusions of $0 \%$, $10 \%, 20 \%$ and $30 \%$ of biscuit bran composed by $50 \%$ of cream and salt and water crackers and $50 \%$ of buttered, chocolate and related biscuits. The weight, weight loss and weight variation, at the end of the lactation period, did not differ statistically for the different biscuit bran inclusion levels. Treatments did not affect the ration consumption, milk yield and bacon thickness of sows or the litter performance. The economic analysis showed better values for diets containing $20 \%$ and $30 \%$ of biscuit bran. It was concluded that the inclusion of biscuit bran was viable up to $30 \%$, in diets for lactating sows, without affecting the sow and litter performance.
\end{abstract}

KEY-WORDS: Alternative ration; litter; swines.

\section{INTRODUÇÃO}

A produção de suínos caracteriza-se pela possibilidade do uso de uma grande diversidade de alimentos, o que permite a constituição de dietas contendo ingredientes alternativos ao milho e farelo de soja, que são preferencialmente utilizados, mas que, nos últimos anos, tiveram aumento significativo de preço, fazendo com que produtores buscassem novas alternativas de produção e novas estratégias para manter a competitividade do agronegócio (Piva et al. 2008).

Segundo Chamone (2011), 60\% da produção nacional de milho e farelo de soja são destinados à alimentação animal, respondendo por $70 \%$ do custo de produção. Neste sentido, a busca por alimentos

\section{RESUMO}

O farelo de biscoito é uma das alternativas que podem ser utilizadas na substituição parcial ou total de ingredientes convencionais, entretanto, é necessário avaliar o impacto de sua inclusão. Assim, foi conduzido um experimento, com o objetivo de avaliar a inclusão de farelo de biscoito em dietas de porcas em lactação. Foram utilizadas 16 porcas em lactação, distribuídas em delineamento inteiramente casualizado, com quatro tratamentos, sendo cada porca considerada uma unidade experimental. Os tratamentos foram compostos por inclusões de $0 \%, 10 \%, 20 \%$ e $30 \%$ de farelo de biscoito, composto por $50 \%$ de biscoito do tipo cream cracker é água e sal e 50\% do tipo amanteigado, achocolatado e afins. A massa, perda de massa e variação de massa das porcas, ao final da lactação, não diferiram, estatisticamente, entre os diferentes níveis de inclusão do farelo de biscoito. Os tratamentos não alteraram o consumo de ração, produção de leite, espessura de toucinho das porcas e desempenho da leitegada. A análise econômica evidenciou melhores valores para as dietas contendo $20 \%$ e $30 \%$ de farelo de biscoito. Concluiu-se que a inclusão de farelo de biscoito foi viável até $30 \%$, em dietas para porcas em lactação, não afetando o desempenho da porca e da leitegada.

PALAVRAS-CHAVES: Ração alternativa; leitegada; suínos.

alternativos, que possam suprir as necessidades dos animais e reduzir os custos de produção, sem comprometer o seu desempenho, é fundamental para os suinocultores, principalmente os de pequeno e médio porte.

O uso de subprodutos da indústria de panificação, como pães, bolos e produtos gerados na própria indústria, dentre estes biscoitos quebrados, amassados, de formato irregular, mal cozidos, queimados ou com características organolépticas anormais (Brasil 1978), que não são destinados ao consumo humano, podem ser considerados alternativas sustentáveis na alimentação animal, ao invés de serem descartados, contaminando o meio ambiente. Assim, o farelo de biscoito, obtido pela moagem de biscoitos ou bolachas, é uma das alternativas que podem ser usadas 
na substituição parcial ou total dos ingredientes convencionais.

O Brasil ocupa a posição de segundo maior produtor mundial de biscoitos, com 1,206 milhões de toneladas produzidas em 2009 (ANIB 2010). Atualmente, existem 585 indústrias de biscoitos no País, com capacidade instalada de 1.700 .000 toneladas, sendo que as 20 maiores representam $75 \%$ do mercado. No entanto, considera-se que uma parte deste volume se perderá, devido a inadequações no processo de produção e distribuição ao consumidor final.

Segundo Boggess et al. (2008), os resíduos da indústria de biscoitos, normalmente, possuem altos valores energéticos, por apresentarem elevados níveis de açúcares e gorduras, e conteúdos de proteína e lisina similares aos do milho, contudo, com valor de sódio mais alto. Segundo De Blas et al. (2003), este subproduto apresenta entre $8 \%$ e $11 \%$ de proteína, com elevada disponibilidade de aminoácidos. Além disto, considera-se o seu caráter de alta palatabilidade, pelo fato de ser obtido de produtos destinados à alimentação humana e que incluem formulações e aditivos melhoradores de características organolépticas. Porém, são raros os trabalhos que analisaram a viabilidade técnica e econômica do uso do farelo de biscoito na alimentação de suínos.

Acrescenta-se a constatação de que muitos trabalhos que avaliam a inclusão de alimentos alternativos são realizados utilizando-se suínos nas fases de crescimento e terminação, enquanto são pouco frequentes aqueles que conduzem protocolos de investigação alimentar ou nutricional voltados a categorias mais delicadas, como porcas em lactação.

Assim, realizou-se este estudo com o objetivo de avaliar o desempenho e a viabilidade econômica da inclusão de farelo de biscoito em dietas de porcas em lactação.

\section{MATERIAL E MÉTODOS}

O experimento foi conduzido no município de Santa Carmem (MT), entre junho e julho de 2011, e seguiu os princípios éticos na experimentação animal sugeridos pelo Colégio Brasileiro de Experimentação Animal. Foram utilizadas 16 porcas na fase de lactação (linhagem Génétiporc ${ }^{\circledR}$ ), distribuídas em delineamento em blocos casualizados, com quatro tratamentos e quatro blocos, sendo cada porca considerada uma unidade experimental, totalizan- do quatro repetições por tratamento. A massa dos animais foi utilizada como critério para a formação dos blocos.

As dietas experimentais foram formuladas à base de milho, farelo de soja, óleo de soja, farelo de biscoito, fosfato bicálcico, calcário calcítico, pré-misturas de vitaminas e minerais, segundo a composição nutricional dos ingredientes e para atender às exigências nutricionais de porcas em lactação (Rostagno et al. 2011). Os tratamentos foram compostos por inclusões de $0 \%, 10 \%, 20 \%$ e $30 \%$ de farelo de biscoito (Tabela 1).

O farelo de biscoito foi obtido a partir do reaproveitamento de produtos recolhidos em uma distribuidora de alimentos, cujos produtos estavam às vésperas do vencimento do prazo de validade para consumo humano, mas apresentando sua embalagem original e boa conservação, sem contaminação química ou microbiana (De Blas et al. 2003).

Tabela 1. Composição centesimal e nutricional das dietas experimentais contendo diferentes inclusões de farelo de biscoito (Santa Carmem, MT, 2011).

\begin{tabular}{lrrrr}
\hline \multirow{2}{*}{ Composição centesimal } & \multicolumn{4}{c}{ Inclusão de farelo de biscoito } \\
\cline { 2 - 5 } & \multicolumn{1}{c}{$0 \%$} & $10 \%$ & $20 \%$ & $30 \%$ \\
\hline Milho & 56,912 & 47,346 & 37,776 & 28,206 \\
Soja farelo & 35,455 & 35,464 & 35,473 & 35,481 \\
Farelo de biscoito & 0,000 & 10,000 & 20,000 & 30,000 \\
Óleo de soja & 3,631 & 3,190 & 2,751 & 2,312 \\
Calcário calcítico & 0,440 & 0,440 & 0,440 & 0,440 \\
Fosfato bicálcico & 2,300 & 2,300 & 2,300 & 2,300 \\
Premix minerais ${ }^{1}$ & 0,100 & 0,100 & 0,100 & 0,100 \\
Premix vitaminas & 0,420 & 0,420 & 0,420 & 0,420 \\
Sal comum & 0,482 & 0,480 & 0,480 & 0,480 \\
Inerte & 0,260 & 0,260 & 0,260 & 0,260 \\
\hline Total & 100 & 100 & 100 & 100 \\
\hline Composição nutricional & & & & \\
Energia met. suínos (kcal kg-1) & 3.400 & 3.400 & 3.400 & 3.400 \\
Proteína bruta (\%) & 20,52 & 20,61 & 20,71 & 20,80 \\
Cálcio (\%) & 0,835 & 0,838 & 0,841 & 0,844 \\
Fósforo disponível (\%) & 0,436 & 0,437 & 0,437 & 0,437 \\
Potássio (\%) & 0,814 & 0,803 & 0,793 & 0,782 \\
Sódio (\%) & 0,210 & 0,226 & 0,243 & 0,260 \\
Lisina digestível (\%) & 1,003 & 1,003 & 1,003 & 1,003 \\
Metionina digestível (\%) & 0,278 & 0,276 & 0,274 & 0,271 \\
Met + Cis digestível (\%) & 0,576 & 0,575 & 0,573 & 0,571 \\
Treonina digestível (\%) & 0,698 & 0,695 & 0,692 & 0,689 \\
Triptofano digestível (\%) & 0,231 & 0,234 & 0,237 & 0,240 \\
Gordura (\%) & 6,293 & 6,425 & 6,558 & 6,692 \\
\hline Coryosiço & & & \\
\hline
\end{tabular}

${ }^{1}$ Composição por kg de produto: Selênio $=300 \mathrm{mg}$; Iodo $=1.500 \mathrm{mg}$; Cobalto $=4.000 \mathrm{mg}$; Cobre $=20.000 \mathrm{mg} ;$ Zinco $=140.000 \mathrm{mg} ;$ Ferro $=$ $180.000 \mathrm{mg}$; Manganês $=80.000 \mathrm{mg} ;$ Veículo $=1.000 \mathrm{~g} .{ }^{2}$ Composição por kg de produto: Vitaminas $\mathrm{A}=12.000 .000 \mathrm{UI}$; D3 $=1.500 .000 \mathrm{UI}$; $\mathrm{E}=20.000 \mathrm{UI}$; K3 $=$ $4.000 \mathrm{mg} ; \mathrm{B} 1=1.000 \mathrm{mg}$; B2 = $4.000 \mathrm{mg}$; B6 = $5.000 \mathrm{mg}$; B12 = $30.000 \mathrm{mg}$; Ácido Nicotínico $=40.000 \mathrm{mg}$; Ácido Pantotênico $=2.000 \mathrm{mg}$; Biotina $=120 \mathrm{mg}$; Ácido Fólico $=600 \mathrm{mg}$; Veículo $=1.000 \mathrm{~g}$. 
O farelo de biscoito foi composto pela proporção de $50 \%$ de biscoitos do tipo cream cracker e água e sal e $50 \%$ do tipo amanteigado, achocolatado e afins. Para compor a dieta experimental, os biscoitos foram moídos em moinho de martelos, com peneiras de $2 \mathrm{~mm}$, produzindo ingrediente com tamanho de partícula similar ao dos demais componentes das rações.

O farelo de biscoito utilizado continha teores de $5,73 \%$ de umidade; $9,06 \%$ de proteína bruta; $12,30 \%$ de gordura; $0,33 \%$ de fibra bruta; $1,18 \%$ de cinzas; $0,10 \%$ de cálcio; e $0,16 \%$ de sódio, sendo estimados os valores de $3.620 \mathrm{kcal} \mathrm{kg}^{-1}$ de energia metabolizável; $0,17 \%$ de lisina digestível; $0,26 \%$ de metionina + cistina digestível; $0,22 \%$ de treonina digestível; $0,08 \%$ de triptofano digestível e $0,06 \%$ de fósforo disponível (Rostagno et al. 2011).

As rações confeccionadas foram identificadas e armazenadas em local protegido de umidade e incidência direta da luz solar. Foram coletadas amostras de cada tratamento para a análise bromatológica (Tabela 2).

As dietas experimentais foram fornecidas logo após o parto, duas vezes ao dia, pela manhã e à tarde (06h00 e 19h00), durante todo o período de lactação. A ração foi fornecida molhada, sendo preparada individualmente em um recipiente, na proporção homogênea de água e ração, conforme o manejo adotado na granja. As sobras foram coletadas e armazenadas em sacos plásticos, para posterior pesagem.

As matrizes foram pesadas aos 6,07 $\pm 1,88$ dias antes do parto, na mesma oportunidade em que foi avaliada a espessura de toucinho, medida com o auxílio de aparelho de ultrassom veterinário (Piemedical-Scanner 200), com sonda linear (ASP-18) de $3,5 \mathrm{MHz}$, à altura da última costela e a, aproximada-

Tabela 2. Composição bromatológica das dietas experimentais contendo diferentes inclusões de farelo de biscoito (Santa Carmem, MT, 2011).

\begin{tabular}{lrrrr}
\hline & \multicolumn{3}{c}{ Inclusão de farelo de biscoito } \\
\cline { 2 - 5 } & \multicolumn{1}{c}{$0 \%$} & $10 \%$ & $20 \%$ & \multicolumn{1}{c}{$30 \%$} \\
\hline Umidade (\%) & 9,99 & 9,30 & 8,86 & 8,46 \\
Proteína bruta (\%) & 20,42 & 20,73 & 21,63 & 21,49 \\
Gordura (\%) & 5,84 & 6,61 & 7,07 & 7,09 \\
Fibra (\%) & 2,99 & 2,64 & 2,63 & 2,59 \\
Cinzas (\%) & 6,69 & 6,51 & 6,49 & 6,27 \\
Cálcio (\%) & 1,54 & 1,47 & 1,61 & 1,37 \\
Fósforo (\%) & 0,59 & 0,56 & 0,57 & 0,54 \\
\hline
\end{tabular}

Valores com base na matéria natural. mente, $6 \mathrm{~cm}$ da linha mediana lombar, do lado direito e esquerdo, extraindo-se a média de ambos.

Após o parto, todos os leitões nascidos vivos foram pesados, bem como os restos placentários, além de natimortos e mumificados. Os leitões nascidos vivos receberam todos os procedimentos adotados pela granja, como corte de dentes, cauda, umbigo e intervenções medicamentosas, quando necessárias.

Na tentativa de equalizar a massa de leitegada, os leitões foram realocados entre as matrizes, no período até 72 horas após o parto, compondo leitegadas entre 10 e 12 leitões. Ao final do período de lactação, que durou 17,06 $\pm 2,53$ dias, procedeu-se ao desmame, avaliando-se o desempenho dos leitões e das porcas, além da espessura de toucinho destas, conforme procedimento adotado no início do experimento. Na sequência, os leitões foram conduzidos ao setor de creche e as fêmeas ao setor de gestação.

Durante todos os dias experimentais, às $08 \mathrm{~h} 00$, foi feita a leitura da temperatura do momento, máxima e mínima e a umidade do ar, por meio de termômetros de mínima e máxima e termohigrômetros. Os dados climáticos foram utilizados para o cálculo do índice de temperatura e umidade (ITU $=0,8 \mathrm{Tbs}+$ UR (Tbs - 14,3)/ $100+46,3$ ) (Buffington et al. 1982).

Com base nos valores monetários dos ingredientes utilizados na formulação das rações e no desempenho das porcas, analisou-se a viabilidade econômica do uso do farelo de biscoito. Os valores foram baseados nos custos dos ingredientes à época da realização do experimento, sendo o custo do farelo de biscoito considerado nulo, tendo-se em vista este ser de não comercialização.

Determinou-se o custo das rações $(C R)$ por quilograma de massa de leitão ganho (Yi), adaptando-se a equação proposta por Bellaver et al. (1985): $Y i=(Q i \times P i) / G i$, em que $Y i=$ custo da ração por quilograma de massa de leitão ganho no $i$-ésimo tratamento; $P i=$ preço por quilograma de ração utilizada no $i$-ésimo tratamento; $Q i=$ quantidade de ração consumida no $i$-ésimo tratamento; e $G i=$ ganho de massa dos leitões no $i$-ésimo tratamento.

Foram calculados o Índice de Eficiência Econômica (IEE) e o Índice de Custo (IC), adaptados de Fialho et al. (1992): $I E E=(M C e i / C T e i) \times 100$ e $I C=$ (CTei/MCei) x 100, em que $M C e i=$ menor custo da ração por quilograma ganho, observado entre os tratamentos, e $C T e i=$ custo do tratamento $i$ considerado.

As variáveis de desempenho foram analisadas pelo Sistema de Análises Estatísticas e Genéticas 
(SAEG), versão 8.0, desenvolvido pela Universidade Federal de Viçosa, utilizando-se os procedimentos para análises de variância. Os dados obtidos foram submetidos à análise de regressão e de variância, a $5 \%$, utilizando-se a covariável de peso da porca ao parto, para os dados de desempenho das porcas, e de peso médio do leitão equalizado, para os dados de desempenho da leitegada.

A produção de leite das porcas foi estimada utilizando-se a seguinte equação: Produção de leite $\left(\mathrm{g} \mathrm{dia}^{-1}\right)=7+[2,5 *$ ganho de peso médio do leitão $(\mathrm{g})]+[80,2 *$ peso inicial do leitão $(\mathrm{kg})] *$ número de leitões (Noblet \& Etienne 1989).

\section{RESULTADOS E DISCUSSÃO}

A temperatura média mensurada durante o experimento foi de $27,4+2,0^{\circ} \mathrm{C}$, com variações entre $19,7^{\circ} \mathrm{C}$ e $35,1^{\circ} \mathrm{C}$ (Tabela 3 ). Observou-se que as temperaturas registradas apresentaram-se acima da zona de conforto dos animais, em comparação às indicações de Nääs (2003), que sugere a faixa de $12-25^{\circ} \mathrm{C}$ como ótima para matrizes suínas. Por outro lado, ao considerar-se o índice de temperatura e umidade (ITU), observou-se valor considerado "brando", segundo Armstrong (1994), cuja classificação sugere valores de 72 a 78, 79 a 88 e 89 a 98, como amenos a brandos, moderados e severos, respectivamente.

Não houve efeito dos tratamentos $(p>0,05)$ sobre a massa corporal das porcas em nenhum momento avaliado. A variação de massa, durante a

Tabela 3. Temperatura mínima, máxima e média, umidade relativa do ar e índice de temperatura e umidade (Santa Carmem, MT, 2011).

\begin{tabular}{ll}
\hline Temperatura mínima $\left({ }^{\circ} \mathrm{C}\right.$, média) & $19,7 \pm 2,1$ \\
Temperatura máxima $\left({ }^{\circ} \mathrm{C}\right.$, média) & $35,1 \pm 2,5$ \\
Temperatura média $\left({ }^{\circ} \mathrm{C}\right)$ & $27,4 \pm 2,0$ \\
Umidade relativa do ar $(\%)$ & $55,2 \pm 7,8$ \\
Índice de temperatura e umidade (ITU) & $75,3 \pm 2,5$ \\
\hline
\end{tabular}

lactação, não foi afetada pela inclusão do ingrediente testado, com valor médio correspondendo a $4,32 \%$, entre os tratamentos (Tabela 4). A inclusão de 30\% de farelo de biscoito gerou perda de massa de $6,30 \%$, durante a lactação, valor acima da indicação de Penz et al. (2009), que consideram que a perda de massa, durante a lactação, pode ser de até $6 \%$.

Também não houve diferença na perda de massa, durante a lactação, entre os tratamentos ( $p>0,05)$, e os valores absolutos apresentaram-se próximos àqueles registrados por Paiva et al. (2006), avaliando diferentes níveis de energia digestível para porcas, ao relatarem perdas entre $8,4 \mathrm{~kg}$ e $14,1 \mathrm{~kg}$, ou equivalentes a 4,8-8,3\%, em temperaturas médias de 17,9-30 ${ }^{\circ} \mathrm{C}$. Contudo, Haese et al. (2010), ao avaliarem ração de alta densidade para porcas em lactação, no verão, observaram que a perda de massa das porcas correspondeu a $2,46 \%$ da massa corporal.

A elevada perda de massa, durante a lactação, observada em todos os tratamentos, pode estar relacionada às elevadas temperaturas registradas e sua influência sobre o consumo e possível recomposição das perdas corporais, devido à produção de leite. Segundo Martins \& Costa (2008), quando as fêmeas são submetidas ao estresse ambiente, pela elevação da temperatura ambiente, são percebidas alterações fisiológicas e comportamentais que interagem, no sentido de tentar manter a homeotermia, consideradas os principais fatores restritivos ao consumo alimentar voluntário, em matrizes suínas, durante a lactação.

A inclusão do farelo de biscoito não influenciou $(p>0,05)$ no consumo de ração das porcas, sendo o consumo médio diário de apenas $3,44 \mathrm{~kg}$ ani$\mathrm{mal}^{-1}$ (Tabela 5), valor abaixo do destacado por Neves (2002), que sugeriu quantias de 6,1-7,6 $\mathrm{kg} \mathrm{dia}^{-1}$, para atingir as necessidades nutricionais com 3,08 Mcal de energia metabolizável.

O baixo consumo observado pode ser considerado um ajuste fisiológico para diminuição do calor e manutenção do equilíbrio homeotérmico (Lima et

Tabela 4. Massa inicial e à desmama, perda e variação de massa de porcas em lactação alimentadas com diferentes níveis de farelo de biscoito (Santa Carmem, MT, 2011).

\begin{tabular}{|c|c|c|c|c|c|}
\hline & \multicolumn{4}{|c|}{ Inclusão do farelo de biscoito } & \multirow{2}{*}{$\mathrm{CV}(\%)$} \\
\hline & $0 \%$ & $10 \%$ & $20 \%$ & $30 \%$ & \\
\hline Massa inicial (kg) & 255,23 & 251,35 & 244,00 & 250,70 & 10,05 \\
\hline Massa à desmama (kg) & 224,07 & 220,07 & 214,15 & 209,42 & 4,37 \\
\hline Perda de massa lactação $(\mathrm{kg})$ & 10,22 & 9,49 & 8,00 & 17,07 & 43,28 \\
\hline Variação de massa lactação (\%) & 4,20 & 3,35 & 3,44 & 6,30 & 26,78 \\
\hline
\end{tabular}


Tabela 5. Consumo de ração, espessura de toucinho e produção de leite de porcas em lactação alimentadas com diferentes níveis de farelo de biscoito (Santa Carmem, MT, 2011).

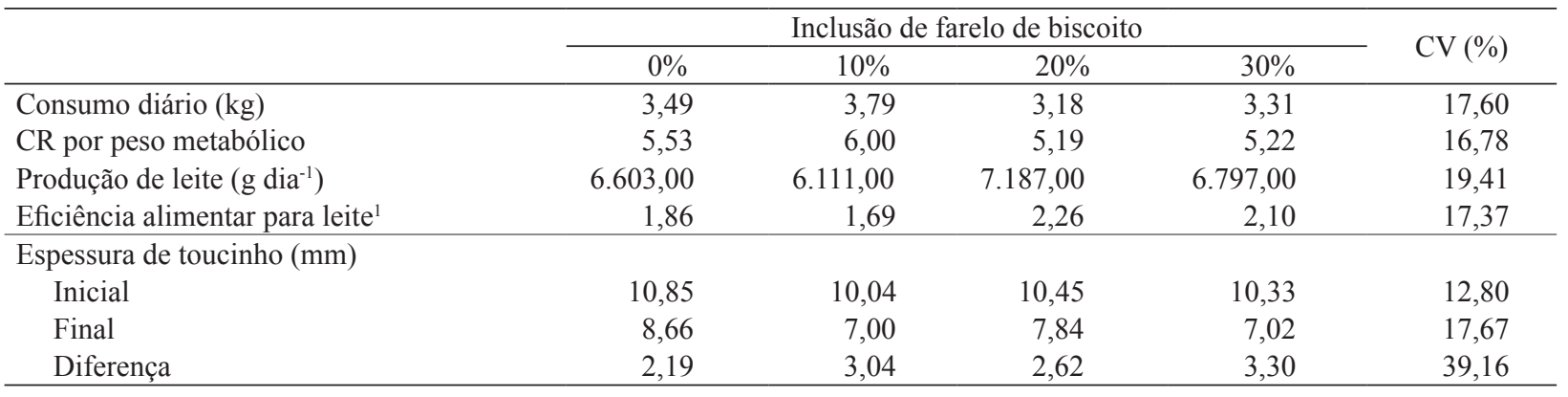

${ }^{1}$ Produção de leite $\left(\mathrm{kg} \mathrm{dia}^{-1}\right) /$ consumo de ração $\left(\mathrm{kg} \mathrm{dia}^{-1}\right)$.

al. 2011). Também, pode-se inferir que o possível incremento de palatabilidade das rações contendo o alimento testado não foi suficiente para diminuir o impacto negativo das altas temperaturas sobre os animais.

Apesar de o farelo de biscoito ser considerado fonte de energia (Gracias 2004), em função do elevado teor de açúcar, amido e gordura (Slominski et al. 2004), seu efeito não foi suficiente para aumentar o consumo, fato também constatado por Solà-Oriol et al. (2009), para leitões, e Chamone (2011), para suínos em terminação. Por outro lado, Kwak \& Kang (2006) observaram que a palatabilidade do resíduo de padaria proporcionou maior consumo em suínos em terminação. Neste sentido, alguns trabalhos (Oliveira \& Lançanova 2001, Kwak \& kang 2006, Narayanan et al. 2009) vêm mostrando que a substituição de ingredientes convencionais pelo farelo de biscoito pode ser de até $50 \%$, com valores nutricionais semelhantes aos de uma dieta à base de milho e farelo de soja.

A produção média de leite foi de $6.675 \mathrm{~g} \mathrm{dia}^{-1}$ e não foi alterada $(p>0,05)$ pelas diferentes inclusões do farelo de biscoito nas dietas das porcas, apresentando-se acima da observada por Paiva et al. (2006), mas abaixo da encontrada por Haese et al. (2010) e Lima et al. (2011). Este resultado pode estar relacionado com o estresse térmico, redução de consumo e diminuição das reservas corporais, pois, segundo Paiva et al. (2005), porcas mantêm a produção de leite utilizando reservas corporais até determinado ponto. Com o avanço da lactação, estas reservas não são mais suficientes para manter a produção, evidenciada, no presente trabalho, pela redução na espessura de toucinho, nos animais avaliados ao início e término da lactação.
A eficiência alimentar para leite não foi afetada pelos tratamentos ( $p>0,05$, Tabela 5), contudo, a inclusão de $20 \%$ e $30 \%$ de farelo de biscoito possibilitou diferenças na ordem de $21,5 \%$ e $12,9 \%$, respectivamente, em relação à ausência do alimento teste.

Não houve diferença significativa entre os tratamentos, para as variáveis relacionadas à espessura de toucinho (Tabela 5). Esta constatação difere do que foi observado por Sirtori et al. (2007), que, ao avaliarem o consumo de resíduos de padaria, em suínos em terminação, encontraram maior ganho de peso e maior espessura de toucinho, sem prejudicar a qualidade de carne.

A espessura média de toucinho, no final da gestação, foi de $10,42 \mathrm{~mm}$, enquanto a perda foi de $2,79 \mathrm{~mm}$, durante a lactação. Ambos os valores estão abaixo do recomendado para a linhagem: $18-20 \mathrm{~mm}$ antes do parto, limitando a perda, durante a lactação, a 2 mm (Génétiporc 2012). Young \& Aherne (2005) consideram que valores abaixo de $14 \mathrm{~mm}$ de espessura de toucinho (ET) podem comprometer a eficiência reprodutiva e, acima de $20 \mathrm{~mm}$, o parto, além de reduzir o consumo de alimento na lactação. Segundo Rossi et al. (2008), a espessura de toucinho ao parto é influenciada pelo número e peso dos leitões nascidos vivos e, durante a lactação, pelo ganho de peso da leitegada, havendo relação com a exigência para a lactonogênese.

$\mathrm{O}$ número de leitões desmamados não foi influenciado $(p>0,05)$ pela inclusão do farelo de biscoito na dieta (Tabela 6). No mesmo sentido, não houve efeito significativo do ingrediente testado sobre o peso da leitegada ao desmame, com valor médio de $52,6 \mathrm{~kg}$. O valor encontrado foi inferior ao obtido $(53,38 \mathrm{~kg})$ por Haese et al. (2010) e superior ao valor médio $(50,92 \mathrm{~kg})$ determinado por Paiva 
et al. (2005), sendo que, em ambos os trabalhos, a lactação teve duração média de 17 dias.

Os parâmetros de ganho de peso da leitegada, do leitão e do leitão por dia não foram influenciados pela inclusão do farelo de biscoito em rações das porcas em lactação (Tabela 6). Esta constatação, possivelmente, está relacionada à não alteração no consumo de alimentos e à consequente produção de leite pelas porcas. Pedreiro et al. (2009) também não observaram diferença do peso ao desmame de leitegada, de porcas recebendo, na dieta, diferentes níveis de inclusão de torta de girassol. No mesmo sentido, Boros et al. (2004), ao incluirem 10\% de subprodutos de padaria, em dietas de frangos de corte, observaram que o ganho de peso e conversão alimentar foram similares aos da dieta controle.

$\mathrm{O}$ ganho de peso médio diário foi de $185 \mathrm{~g}$, sendo o leite a única fonte de alimento da leitegada, durante a lactação. Este resultado foi semelhante ao encontrado por Cota et al. (2003), com peso médio de 188,4 g, avaliando desmame com 21 dias, mas inferior ao observado por Haese et al. (2010), com média de 199,5 g, analisando leitões desmamados aos 17 dias. Segundo Martins et al. (2007), a ausência de ração pré-inicial, devido à necessidade de calcular a produção de leite, pode ter contribuído para este resultado.

O uso de dietas contendo até $30 \%$ de farelo de biscoito não alterou o desempenho das porcas e suas leitegadas, em relação à dieta sem o uso do ingrediente teste, viabilizando a sua utilização. Esta condição contradiz as sugestões de inclusão de até $12 \%, 10 \%$ e $20 \%$, para porcas em lactação, feitas, respectivamente, por De Blas et al. (2003), Boggess et al. (2008) e Rostagno et al. (2011).

O custo de ração por quilograma de ganho de peso da leitegada, índice de eficiência econômica (IEE) e índice de custo (IC) evidenciaram melhores valores $(\mathrm{p}>0,05)$ para as dietas contendo $20 \%$ e $30 \%$ de inclusão de farelo de biscoito, em relação às demais (Tabela 7). Isto está relacionado à maior inclusão do ingrediente testado, bem como à menor inclusão de milho e óleo de soja, reduzindo o custo das dietas.

Observou-se que a inclusão do farelo de biscoito permitiu reduzir a inclusão de milho nas dietas, sem alterar o desempenho dos animais, fato importante, tendo-se em vista a grande participação

Tabela 6. Desempenho de leitegada, em período de lactação, de porcas alimentadas com diferentes níveis de farelo de biscoito (Santa Carmem, MT, 2011).

\begin{tabular}{|c|c|c|c|c|c|}
\hline & \multicolumn{4}{|c|}{ Inclusão de farelo de biscoito } & \multirow{2}{*}{$\mathrm{CV}(\%)$} \\
\hline & $0 \%$ & $10 \%$ & $20 \%$ & $30 \%$ & \\
\hline \multicolumn{6}{|l|}{ Número de leitões } \\
\hline Desmamados & 11,25 & 11,00 & 11,25 & 11,75 & 9,29 \\
\hline \multicolumn{6}{|l|}{ Peso da leitegada (kg) } \\
\hline Equalizada & 16,60 & 14,85 & 18,15 & 18,12 & 17,20 \\
\hline Desmamada & 51,90 & 50,11 & 54,55 & 54,70 & 21,32 \\
\hline \multicolumn{6}{|l|}{ Peso médio leitão (kg) } \\
\hline Equalizado & 1,48 & 1,36 & 1,61 & 1,54 & 16,24 \\
\hline Desmamado & 4,65 & 4,59 & 4,88 & 4,63 & 21,73 \\
\hline \multicolumn{6}{|l|}{ Ganho de peso (kg) } \\
\hline Por leitegada & 35,30 & 35,26 & 36,40 & 36,57 & 26,31 \\
\hline Por leitão & 3,16 & 3,23 & 3,26 & 3,09 & 27,24 \\
\hline Diário por leitão & 0,185 & 0,177 & 0,202 & 0,177 & 20,78 \\
\hline
\end{tabular}

Tabela 7. Avaliação econômica do desempenho de porcas lactantes alimentadas com diferentes níveis de farelo de biscoito (Santa Carmem, MT, 2011).

\begin{tabular}{|c|c|c|c|c|c|}
\hline & \multicolumn{4}{|c|}{ Inclusão de farelo de biscoito } & \multirow{2}{*}{$\mathrm{CV}(\%)$} \\
\hline & $0 \%$ & $10 \%$ & $20 \%$ & $30 \%$ & \\
\hline Custo de ração por quilograma de ganho de peso da leitegada $\left(\mathrm{R} \$ \mathrm{~kg}^{-1}\right)$ & $11,07 \mathrm{a}$ & $11,03 \mathrm{a}$ & $7,35 \mathrm{~b}$ & $7,93 \mathrm{~b}$ & 18,87 \\
\hline Índice de eficiência econômica $(I E E)$ & $55,73 \mathrm{a}$ & $56,80 \mathrm{a}$ & $81,78 \mathrm{~b}$ & $78,87 \mathrm{~b}$ & 20,62 \\
\hline Índice de custo $(I C)$ & $185,88 \mathrm{a}$ & $185,16 \mathrm{a}$ & $123,42 \mathrm{~b}$ & $133,05 \mathrm{~b}$ & 18,87 \\
\hline
\end{tabular}

Diferença: Duncan, a $5 \%$. 
deste ingrediente em rações para suínos. No mesmo sentido, constatou-se que é viável substituir, parcialmente, o óleo de soja pelo farelo de biscoito, devido ao nível de gordura presente no ingrediente testado, que apresenta-se maior, em relação a outros ingredientes energéticos, como os cereais. Desta forma, é possível reduzir os custos das dietas, tendo-se em vista o elevado custo do óleo de soja.

\section{CONCLUSÕES}

1. O farelo de biscoito pode ser incluído na dieta de porcas em lactação em até $30 \%$, não afetando o peso, a espessura de toucinho e o consumo de ração.

2. A inclusão de até $30 \%$ de farelo de biscoito em dietas de porcas em lactação não afetou a produção de leite e o desempenho da leitegada.

3. A inclusão de $20 \%$ e $30 \%$ de farelo de biscoito na dieta de porcas em lactação melhorou a viabilidade econômica.

\section{REFERÊNCIAS}

ARMSTRONG, D. V. Heat stress interaction with shade and cooling. Journal of Dairy Science, West Gregory, v. 77, n. 7, p. 2044-2050, 1994.

ASSOCIAÇÃO NACIONAL DAS INDÚSTRIA DE BISCOITO (ANIB). Estatísticas do mercado de biscoitos. 2010. Disponível em: $<\mathrm{http}: / / w w w . a n i b . c o m . b r>$. Acesso em: 28 ago. 2012.

BELLAVER, C. et al. Radícula de malte na alimentação de suínos em crescimento e terminação. Pesquisa Agropecuária Brasileira, Brasília, DF, v. 20, n. 8, p. 969 974, 1985.

BRASIL. Comissão Nacional de Normas e Padrões para Alimentos (CNNPA). Resolução CNNPA n ${ }^{\circ}$ 12, de 24 de julho de 1978. Aprova as normas técnicas especiais. Diário Oficial da República Federativa do Brasil, Brasília, DF, 24 jul. 1978. Disponível em: <http://www.anvisa.gov.br/ legis/resol/12_78.pdf > . Acesso em: 30 jul. 2012.

BOGGESS, M.; STEIN, H. H.; DEROUCHEY, J. Alternative feed ingredients in swine diets. 2008. Disponível em: <http://www.pork.org/filelibrary/ AnimalScience/Alternative\%20Feed\%20Brochure.pdf $\$$. Acesso em: 19 jul. 2011.

BOROS, D. et al. Wheat by-products in poultry nutrition: Part II. Nutritive value of wheat screenings, bakery byproducts and wheat mill run and their improved utilization by enzyme supplementation. Canadian Journal of Animal Science, Ottawa, v. 84, n. 3, p. 429-435, 2004.
BUFFINGTON, D. E.; COLLIER, R. J.; CANTON, G. H. Shade management systems to reduce heat stress for dairy cows. St. Joseph: American Society of Agricultural Engineers, 1982.

CHAMONE, J. M. A. Resíduo de bolacha em rações para suínos na fase de terminação. 2011. 85 f. Dissertação (Mestrado em Produção Animal) - Universidade Estadual de Montes Claros, Montes Claros, 2011.

COTA, T. S. et al. Níveis de lisina em rações para fêmeas suínas primíparas. Revista Brasileira de Zootecnia, Viçosa, v. 32, n. 1, p. 115-122, 2003.

DE BLAS, C.; MATEOS, G. G.; REBOLLAR, P. G. Tablas FEDNA de composición y valor nutritivo de alimentos para la formulación de piensos compuestos. 2. ed. Madrid: FEDNA, 2003.

FIALHO, E. T. et al. Utilização da cevada suplementada com óleo de soja para suínos em crescimento e terminação. Pesquisa Agropecuária Brasileira, Brasília, DF, v. 27, n. 10, p. 1467-1475, 1992.

GRACIAS, R. A. B. Comparacion entre el método de estimacion matemática y el método de calorimetría para determinar el contenido energético del subproducto de galleta y de panadería para la alimentacion de cerdos em desarrollo. 2004. 46 f. Tesis (Licenciado en Zootecnia) Facultad de Medicina Veterinária y Zootecnia, Escuela de Zootecnia, Universidad San Carlos de Guatemala, Guatemala, 2004.

HAESE, D. et al. Avaliação de rações de alta densidade nutricional para porcas em lactação no verão. Revista Brasileira de Zootecnia, Viçosa, v. 39, n. 7, p. 1503-1508, 2010.

KWAK, W. S.; KANG, J. S. Effect of feeding food wastebroiler litter and bakery by-product mixture to pigs. Animal Science Bioresource Technology, Oxford, v. 97, n. 2, p. 243-249, 2006.

LIMA, A. L. et al. Resfriamento do piso da maternidade para porcas em lactação no verão. Revista Brasileira de Zootecnia, Viçosa, v. 40, n. 4, p. 804-811, 2011.

GÉNÉTIPORC. Manual Génétiporc: nutrição e alimentação de reprodutores, biossegurança de granja e transporte. S.d. Disponível em: $<$ http://www.genetiporc. com/download/Manual_Reprodutores_Genetiporc.pdf $>$. Acesso em: 24 jul. 2012.

MARTINS, T. D. D. et al. Produção e composição do leite de porcas híbridas mantidas em ambiente quente. Ciência Rural, Santa Maria, v. 37, n. 4, p. 1079-1083, 2007.

MARTINS, T. D. D.; COSTA, A. N. Desempenho e comportamento de fêmeas suínas lactantes criadas em climas tropicais. Archivos de Zootecnia, Córdoba, v. 57, n. 1, p. $77-88,2008$. 
NÄÄS, I. A. O ambiente e a resposta reprodutiva de fêmeas suínas. Revista Suínos \& Cia., Paulínea, v. 1, n. 4, p. 8-13, 2003.

NARAYANAN, R. et al. Biscuit powder as an unconventional feed in piglets. Indian Journal of Animal Research, Haryana, v. 43, n. 3, p. 215-216, 2009.

NEVES, J. F. Atualização na nutrição de porcas gestantes e lactantes. In: CONGRESSO LATINO-AMERICANO DE SUINOCULTURA, 1., 2002, Foz do Iguaçú. Anais... Foz do Iguaçú: Porkworld, 2002. p. 165-199.

NOBLET, J.; ETIENNE, M. Estimation of sow milk nutrient output. Journal of Animal Science, Champaign, v. 67, n. 12 , p. 3352-3359, 1989.

OLIVEIRA, M. D. S.; LANÇANOVA, J. A. C. Efeito da substituição do milho pelo resíduo de biscoito na digestibilidade in vitro da matéria seca, da proteína bruta e da energia bruta. ARS Veterinária, Jaboticabal, v. 17, n. 3, p. 249-253, 2001.

PAIVA, F. P. et al. Lisina em rações para fêmeas suínas primíparas em lactação. Revista Brasileira de Zootecnia, Viçosa, v. 34, n. 6, p. 1971-1979, 2005.

PAIVA, F. P. et al. Energia digestível em rações para porcas primíparas em lactação. Arquivo Brasileiro de Medicina Veterinária e Zootecnia, Belo Horizonte, v. 58, n. 2, p. 234-241, 2006.

PEDREIRO, G. E. G. et al. Torta de girassol na alimentação de matrizes suínos em gestação e lactação. Ciências Agrárias, Londrina, v. 30, n. 2, p. 497-504, 2009.

PENZ, A. M.; BRUNO, D.; SILVA, G. Interação nutriçãoreprodução em suínos. Acta Scientiae Veterinariae, Porto Alegre, v. 37, supl., p. 183-194, 2009.
PIVA, J. H. et al. Gerenciamento da produção em um novo cenário mundial de custo de alimento. In: FÓRUM INTERNACIONAL DE SUINOCULTURA; SEMINÁRIO TÉCNICO DE MANEJO E PRODUÇÃO, 4., 2008, Curitiba. Anais... Curitiba: Animal World, 2008. p. $526-531$.

ROSSI, C. A. R. et al. Metanálise da relação entre espessura de toucinho e variáveis corporais e reprodutivas de porcas gestantes e lactantes. Ciência Rural, Santa Maria, v. 38, n. 1, p. 206-212, 2008.

ROSTAGNO, H. S. et al. Tabelas brasileiras para aves e suínos: composição de alimentos e exigências nutricionais. 3. ed. Viçosa: UFV, 2011.

SIRTORI, F.; ACCIAIOLI, A.; PIANACCIOLI, L. Effect of use of bread in fattening of Cinta Senese pig. Italian Journal of Animal Science, Pavia, v. 6, supl., p. 719-721, 2007.

SLOMINSKI, B. A. et al. Wheat by-products in poultry nutrition: Part I. Chemical and nutritive composition of wheat screenings, baker by-products and wheat mill run. Canadian Journal of Animal Science, Ottawa, v. 84, n. 3, p. 421-428, 2004.

SOLÀ-ORIOL, D.; ROURA, E.; TORRALLARDONA, D. Feed preference in pigs: effect of cereal sources at different inclusion rates. Journal of Animal Science, Champaign, v. 87, n. 2, p. 562-570, 2009.

YOUNG, M.; AHERNE, F. Monitoring and maintaining sow condition. Advanced Pork Production, Saskatoon, v. 16, n. 1, p. 299-313, 2005. 